\title{
Biochemical Characterization of a Group-5 Soluble Diiron Monooxygenase Hydroxylase and Related Chaperonin-like Component
}

\author{
Chihiro Inoue, Yoshitaka Abe, Nobutaka Fujieda*
}

Division of Applied Life Sciences, Graduate School of Life and Environmental Sciences, Osaka Prefecture University, 1-1 Gakuen-cho, Nakaku, Sakai-shi, Osaka 599-8531, Japan

\begin{abstract}
Soluble diiron monooxygenases are observed in a wide range of microorganisms and have garnered significant interest as oxidation biocatalysts owing to their ability to catalyze the oxygenation of a variety of aliphatic/aromatic hydrocarbons. They can be categorized into six groups based on the types of substrate, sequences, and component arrangement on the gene cluster. Earlier, the expression of several groups of such soluble diiron monooxygenases in representative heterologous hosts, such as Escherichia coli, was considered to be difficult. However, the functional expression of group-5 hydroxylase component (MimA and MimC) in Escherichia coli along with its related chaperonin-like component (MimG) was reported recently. Here, we describe their purification via a heterologous expression system and the biochemical characterization of MimAC, the complex of MimA and MimC and MimG to obtain insights into their structure and exact roles. MimAC and MimG were fused with His-tags and purified using affinity chromatography in a homogenous state on sodium dodecyl sulfate-polyacrylamide gel electrophoresis. Blue native polyacrylamide gel electrophoresis demonstrated that the quaternary structure of MimG was almost identical to that of GroEL expressed in $E$. coli, indicating that its function was also similar to GroEL. Size-exclusion chromatography and inductively coupled plasma analysis demonstrated that MimAC was assembled in $(\alpha \beta)_{2}$ configuration and exhibited two iron atoms and at least one zinc atom per $\alpha \beta$ complex. This result indicated that MimAC possessed a dinuclear iron center, similar to other soluble diiron monooxygenase hydroxylases.
\end{abstract}

\section{INTRODUCTION}

Gaseous alkanes are abundantly found in natural gas, which is an ideal and low-cost alternative carbon source, making it an appealing feedstock for value-added chemicals and fuels. ${ }^{1,2}$ Due to the stability of the $\mathrm{C}-\mathrm{H}$ bonds in short-chain alkanes such as methane, ethane, and propane, upgrading these compounds is one of the most significant challenges in catalysis. ${ }^{3-5}$ In nature, some bacteria can convert such alkanes to alcohols under ambient temperature using hydrocarbon monooxygenases. This monooxygenase family includes a variety of enzymes such as cytochrome P450, flavin-dependent monooxygenase, AlkBrelated alkane hydroxylases, soluble diiron monooxygenases (SDIMO), and particulate methane monooxygenases (pMMO) observed in organisms ranging from microorganisms to plants and animals. ${ }^{5-7}$ Among these, SDIMOs are a diverse group of non-heme diiron enzymes that activate dioxygen and have garnered significant interest owing to high sequence diversity, broad substrate range, and various applications. ${ }^{5}$ Notably, soluble methane monooxygenases (sMMO) and butane monooxygenases (BMO) are of primary interest owing to their ability of oxidizing short-chain alkanes. ${ }^{8}$ For this reason, sMMOs and BMOs are the most well-characterized members of this monooxygenase family with respect to their biochemistry and structure. ${ }^{9-12}$ On the other hands, the biochemical properties of propane monooxygenases (PMO) are not less well understood, although they can also catalyze the oxidation of light alkanes. $^{13,14}$

Recently, SDIMOs were categorized into six groups of enzymes based on their structure and substrate specificity rooted in phylogenetic relationships. ${ }^{15-18}$ sMMOs and BMOs is belonging to group-3 of SDIMO family and contain a dimeric hydroxylase protein with three subunits in $(\alpha \beta \gamma)_{2}$ stoichiometry along with the reductase and regulatory proteins. ${ }^{19}$ The hydroxylase component exhibits a $(\alpha \beta \gamma)_{2}$ heterohexameric structure in phenol hydroxylate (group-1) ${ }^{20}$ and toluene 4monooxygenase (group-2). ${ }^{21}$ The alkene monooxygenase (group-4) hydroxylase differs in owing to the presence of only the $\alpha$ - and $\beta$-subunits, which are arranged as $\alpha \beta$ monomers. ${ }^{22}$ There is no experimental evidence demonstrating the structures of the hydroxylase component of PMOs (group-5), although they are presumed to possess $(\alpha \beta)_{2}$ dimeric structure based on the analogy with the hydroxylase component of groups $1-3 .{ }^{16}$

To facilitate the understanding of SDIMO enzymology and improve their efficacy in various applications, heterologous expression systems of enzymes belonging to group- 1 and -2 in hosts such as $E$. coli have been constructed. ${ }^{23}$ It is worth noting that the coexpression of the GroEL-like protein, namely, MimG from Mycolicibacterium smegmatis, enabled the functional expression of a group-5 SDIMOs (MimABCD) from Mycolicibacterium goodii in E. coli, ${ }^{24}$ despite the resistance of group-3 and -6 SDIMOs to this approach and production of insoluble and/or inactive proteins in $E$. coli. ${ }^{25,26}$ In the $\operatorname{mim} \mathrm{ABCD}$ gene cluster, $\operatorname{mim} A$ and $\operatorname{mim} C$ encode the hydroxylase component, and $\operatorname{mim} B$ and $\operatorname{mim} D$ encode the reductase and the regulatory proteins, respectively. ${ }^{27}$ In addition, the gene encoding the chaperonin-like protein, $\operatorname{mim} \mathrm{G}$ is present on the gene cluster. ${ }^{28}$ MimG is homologous to GroEL that assists newly synthesized polypeptides is folded correctly and prevents aggregation and precipitation of the folded proteins. E. coli transformed with the plasmid containing mim $A$ and $\operatorname{mim} C$ does not demonstrate any catalytic activity without the co-expression of the $\operatorname{mim} G$ gene. ${ }^{24}$ Such a GroEL-like protein-encoding genes, $m m o \mathrm{G}$ and $b m o \mathrm{G}$ were also observed in the gene cluster involving genes encoding MMOs and BMOs (group-3), respectivly and are involved in the transcriptional activation of SDIMO genes in the native host. ${ }^{29-31}$ Accordingly, MimG and $\mathrm{MmoG}$ have been postulated to function as molecular chaperones. Attempts to purify the GroEL-like protein have not been successful ${ }^{30}$; however, purification of these GroEL-like proteins is essential for the determination of their exact role. Thus, this study aimed to isolate and biochemically characterize the GroEL-like protein and the hydroxylase component of group- 
5 SDIMO in order to obtain significant insight into the function of the SDIMO-associated GroEL-like protein.

\section{MATERIALS AND METHODS}

\section{Reagents}

The plasmids pCDFDuet1, pRSFDuet1 were obtained from Novagen Inc. (Madison, WI, USA). The plasmid pGro7 was obtained from Takara Bio Inc. (Shiga, Japan). Iron(III) citrate and COSMOGEL His-Accept was obtained from Nacalai Tesque. (Kyoto, Japan). Iron and zinc standard solutions were obtained from Fujifilm Wako Chemicals Co. (Osaka, Japan). Ammonium iron(III) citrate was obtained from Kanto Chemicals Co. (Tokyo, Japan). All other chemicals used were of reagent grade.

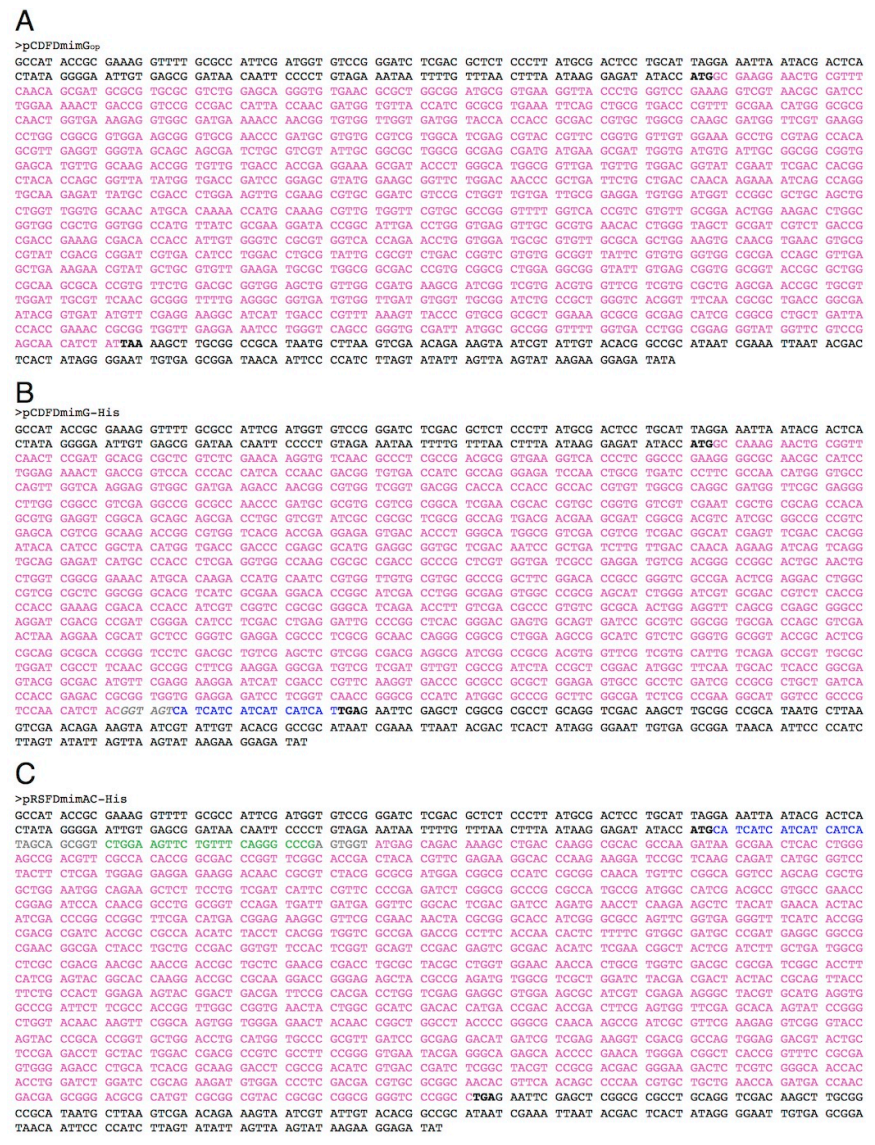

Figure 1. The DNA sequences spanning the multi-cloning site in expression plasmids. (A) $\mathrm{pCDFDmimG}_{\mathrm{op}}$, (B) pCDFDmimG-His, and (C) pRSFDmimAC-His. The $\operatorname{mim} \mathrm{G}$ and $\operatorname{mim} \mathrm{A}$ sequences are highlighted in pink; the His-tag gene, the recognition sequence of HRV-3C, and linker regions are highlighted in blue, green, and grey, respectively. Initiation and termination codons are indicated in bold.

\section{Plasmids and Site-directed Mutagenesis}

For the expression of Mycolicibacterium MimG protein, pCDFDuet1-based expression constructs containing the native DNA sequence and codon-optimized sequence were used. The DNA fragments of $\operatorname{mim} G$ were purchased from GenScript Japan Inc. (Tokyo, Japan). The fragment containing the native sequence was cloned into the pCDFDuet-1 vector between the NcoI and EcoRI sites resulting in pCDFDmimG vector, in accordance with a previously published protocol. ${ }^{24}$ The fragment containing the codon-optimized sequence was cloned into the same vector between NcoI and HindIII sites to construct the pCDFDmimGop vector (Fig. 1A).

For the expression of Mycolicibacterium MimAC, the previously reported plasmid based expression construct was used .${ }^{24}$ The DNA fragments of $\operatorname{mim} A$ and $\operatorname{mim} C$ containing native sequences were purchased from GenScript Japan Inc. (Tokyo, Japan). The pRSFDuet1-based expression constructs were used for the expression of native DNA sequences of $\operatorname{mim} A$ and $\operatorname{mim} C$. The fragments containing native sequences of $\operatorname{mim} A$ and $\operatorname{mim} C$ were cloned into pRSFDuet1 vector between NcoI and EcoRI and NdeI and Xho I sites, respectively, resulting in the pRSFDmimAC vector in accordance with a previously published report. $^{24}$

His-tag coding sequences were introduced into the sequences of mim $G$ in pCDFDmimG, mimA in pRSFDmimAC, and groEL in pGro7 using oligonucleotide-directed mutagenesis. The pair of mutagenic oligonucleotides was purchased from Macrogen Japan (Tokyo, Japan). (5'-GAA TTC GAG CTC GGC GCG CCT GCA GGT CGA-3' and 5'-TCA ATG ATG ATG ATG ATG ATG ACT ACC GTA GAT GTT GGA CGG GCG GAC CAT GC-3' for pCDFDmimG, 5'-CT GGA AGT TCT GTT TCA GGG CCC GAG TGG TAT GAG CAG ACA AAG CCT GAC CAA GGC GCA C-3' and 5'-ACC GCT GCT ATG ATG ATGAT GAT GAT GCA TGG TAT ATC TCC TTA TTA AAG TTA AAC AAA ATT ATT TCT AC-3' for pRSFDmimAC, 5'TAG CAG CCA TCA TCA TCA TCA TCA TTA ATT GCC CTG CAC CTC GCA GAA ATA AAC AAA CC -3' and 5'CCC GGG CCC TGA AAC AGA ACT TCC AGA CTA CCC ATC ATG CCG CCC ATG CCA CCC ATG CC-3' for pGro7). Mutagenesis was performed with inverse PCR. This was followed by DpnI digestion and self-ligation to synthesize pCDFDmimG-His from pCDFDmimG, pRSFDmimAC-His from pRSFDmimAC (Fig. 1B, C, and Fig. 2), and pGro7-His from pGro7. The resulting gene sequences were validated by DNA sequencing using a 3730xl DNA Analyzer (Life Technologies) after the construction of the vector.

\section{A}

$>$ His-tag fused MimG

MAKEL RFNSD ARARL EQGVN ALADA VKVTL GPKGR NAILE KLTGP PTITN DGVTI AREIQ LRDPF ANMGA QLVKE VAMKT NGVVG DGTTT ATVLA QAMVR EGLAA VEAGA NPMRV RRGIE RTVPV VVESL RSHSV EVGSS SDLRR IAALA ASDDE AIGDV IAAAV EHVGK TGVVT TEESD TLGMA VDVVD GIEFD HGYTS GYMVT DPERM EAVLD NPLIL LTNKK ISQVQ EIMPT LEVAK RADRP LVVIA EDVDG PALQL LVGGN MHKTM QSVVV RAPGF
GHRRV AELED LAVAL GGHVI AKDTG IDLGE VAREH LGSCD RLTAT ESDTT IVGPR GHQNL VDARV AQLEV QRERA RIDAD RDILD LRIAR LTGRV AVIRV GGATS VELKE RMLRV EDALA ATRAA LEAGI VSGGG TALAQ
AHRVL DAVEL VGDEA IGRDV VRRAL SEPLR WIAFN AGFEG GDVVD VVADL PLGHG FNALT GEYGD MFEEG IIDPF KVTRA ALESA ASIAA LLITT ETAVV EEILG QPGAI MAPGF GDLAE GMVRP SNIYG SHHHH HH

\section{B}

$>$ His-tag fused MimA

MHHHH HHSSG LEVLF QGPSG MSRQS ITKAH AKISE LTWEP TFATP ATRFG TDYTF EKAPK KDPLK QIMRS YFSME EERDN RVYGA MDGAI RGNMF RQVQQ RWLEW QKLFL SIIPF PEISA ARAMP MAIDA VPNPE IHNGL AVOMI DEVRH STIOM NLKKL YMNNY IDPAG FDMTE KAFAN NYAGT IGROF GEGFI TGDAI TAANI YLTVV AETAF TNTLF VAMPD EAAAN GDYLL PTVFH SVQSD ESRHI SNGYS ILLMA LADER NRPLL ERDLR YAWWN
NHCVV DAAIG TFIEY GTKDR RKDRE SYAEM WRRWI YDDYY RSYLI PLEKY GLTIP HDLVE EAWKR IVEKG YVHEV ARFFA TGWPV NYWRI DTMTD TDFEW FEHKY PGWYN KFGKW WENYN RLAYP GRNKP IAFEE VGYQY PHRCW TCMVP ALIRE DMIVE KVDGQ WRTYC SETCY WTDAV AFRGE YEGRA TPNMG RLTGF REWET LHHGK DLADI VTDLG YVRDD GKTLV GQPHL DLDPQ KMWTL DDVRG NTFNS PNVLL NOMTN DERDA HVAAY RAGGV

Figure 2. Amino acid sequence of the His-tag fused proteins. (A) Histag fused MimG and (B) His-tag fused MimA. The mim G and $\operatorname{mim} \mathrm{A}$ sequences are indicated in black; His-tag gene, the recognition sequence of HRV-3C, and linker regions are highlighted in red, blue, and green, respectively.

\section{Expression and purification of proteins}

The chaperonin, namely, GroEL, was induced with the addition of ${ }_{\mathrm{L}}$-arabinose and purified from $E$. coli BL21(DE3) containing pGro7-His according to a previously published protocol. ${ }^{32}$ For the isolation of MimG, E. coli cells (Rosetta 2(DE3)) containing pCDFmimG-His were cultured in an autoinduction medium 
$(\mathrm{ZY}-5052)^{33}$ containing $50 \mu \mathrm{g} / \mathrm{mL}$ streptomycin and $20 \mu \mathrm{g} / \mathrm{mL}$ chloramphenicol at $37{ }^{\circ} \mathrm{C}$ and $135 \mathrm{rpm}$ for $5 \mathrm{~h}$, followed by further incubation at $25{ }^{\circ} \mathrm{C}$ and $135 \mathrm{rpm}$ for $16 \mathrm{~h}$. Overnight cultures were harvested by the centrifugation at $5000 \times \mathrm{g}$ for 30 min at $4{ }^{\circ} \mathrm{C}$. Cells were disrupted in $10 \mathrm{mM}$ bis-Tris (pH 7.2) and $0.5 \mathrm{M} \mathrm{NaCl}$ (buffer A) with sonication. Subsequent centrifugation for $1 \mathrm{~h}$ at $4^{\circ} \mathrm{C}$ with $30,000 \times g$ yielded cell-free lysates containing the MimG protein. Purification was performed by affinity chromatography using a Ni-Sepharose (COSMOGEL His-Accept) $\quad 10 \mathrm{~mL}$ column with buffer $\mathrm{A}$ as equilibration/washing buffer and buffer $\mathrm{A}+0.5 \mathrm{M}$ imidazole as elution buffer.

For the isolation of the MimAC complex, E. coli cells (Rosetta 2(DE3)) were co-transformed with two plasmids, namely, pCDFmimG and pRSFmimAC-His, and cultured in lysogeny broth with $50 \mu \mathrm{g} / \mathrm{mL}$ streptomycin and $50 \mu \mathrm{g} / \mathrm{mL}$ kanamycin at $37^{\circ} \mathrm{C}$ and $135 \mathrm{rpm}$ until the optical density $(600$ $\mathrm{nm}$ ) reached 0.5 . The protein expression was induced with 0.1 $\mathrm{mM}$ isopropyl- $\beta$-D-thiogalactopyranoside, and $E$. coli cells were subsequently cultured at $25^{\circ} \mathrm{C}$ and $135 \mathrm{rpm}$ in the presence of $250 \mu \mathrm{M}$ ammonium iron(III) citrate and $250 \mu \mathrm{M}$ iron(III) citrate. Overnight cultures were harvested by centrifugation at $5000 \times g$ for $30 \mathrm{~min}$ at $4{ }^{\circ} \mathrm{C}$. Cells were disrupted in $10 \mathrm{mM}$ bis-Tris $(\mathrm{pH}$ 7.2) and $0.5 \mathrm{M} \mathrm{NaCl}$ (buffer A) by sonication. Subsequent centrifugation for $1 \mathrm{~h}$ at $4{ }^{\circ} \mathrm{C}$ with $30,000 \times g$ yielded cell-free lysates containing the MimG protein. Purification was performed using affinity chromatography with a Ni-Sepharose $10 \mathrm{~mL}$ column (COSMOGEL His-Accept) and buffer $\mathrm{A}$ as the equilibration/washing buffer and buffer $\mathrm{A}+0.5 \mathrm{M}$ imidazole as elution buffer. To excise the His-tag region from the protein, aliquots of HRV3C protease were added to the collected fraction, followed by incubation in the buffer at $4{ }^{\circ} \mathrm{C}$ overnight. The protein solution was dialyzed against $10 \mathrm{mM}$ Tris- $\mathrm{HCl}$ buffer (pH 7.2) containing $10 \mathrm{mM} \mathrm{NaCl}$ (buffer B) at $4{ }^{\circ} \mathrm{C}$ to remove excess imidazole and $\mathrm{NaCl}$. Subsequently, anion exchange chromatography was performed using a Hitrap Q $5 \mathrm{~mL}$ column (Cytiva) with buffer $\mathrm{B}$ as equilibration/washing buffer. The protein was eluted with a 20-column volume linear gradient of $\mathrm{NaCl}$ (10-500 $\mathrm{mM})$. The fractions containing the purified proteins were collected and concentrated by ultrafiltration using Vivaspin turbo 15 (Sartorius AG, Göttingen, Germany). The protein samples were stored at $-80{ }^{\circ} \mathrm{C}$ until further use. Purity was determined using SDS-PAGE. Protein concentration was determined by measuring the intensity of absorbance at 280 $\mathrm{nm} .{ }^{34}$ Densitometry analysis of the gel bands was performed using the ImageJ software. Electrospray ionization-mass spectra were obtained using the Agilent LC/MSD (G6125B) system.

\section{Analysis of subunit structures}

Blue native gel electrophoresis was performed using NativePAGE 4-16\% Bis-Tris Gels according to the manufacturer's instructions (Invitrogen, Carlsbad, CA, USA). Gel filtration was performed using a Superdex 200 10/300 GL column (Cytiva) and a neutral buffer (50 $\mathrm{mM}$ phosphate containing $150 \mathrm{mM} \mathrm{KCl}$ at $\mathrm{pH} \mathrm{7.0)}$ was used as an eluent. Aldorase (158 kDa), conalbumin (75 kDa), ovalbumin (44 kDa), carbonic anhydrase $(29 \mathrm{kDa})$, and ribonuclease A $(14 \mathrm{kDa})$ were used as marker proteins for the determination of molecular mass.

\section{Inductively coupled plasma atomic emission spectroscopy} (ICP-AES)

The presence of metallic components was determined using ICPAES with the ICPS-8100 emission spectrometer (Shimadzu). The calibration curves of the metal ions were constructed using the metal ion standard solution $(10.0 \mathrm{ppm})$. The purified protein was dialyzed against $5 \mathrm{mM}$ sodium phosphate buffer at $\mathrm{pH} 7.0$ and the resulting samples was subjected to ICP analysis.

\section{RESULTS AND DISCUSSION}

\section{Optimization of expression construct of MimG}

A GroEL-like protein, namely, MimG derived from $M$. smegmatis was expressed in the soluble fraction obtained from E. coli in accordance with previous reports. ${ }^{24}$ The protein was produced even with the use of an autoinduction medium (ZY$5052)^{33}$ instead of the commonly used IPTG induction method (Fig. 3A). Cell lysates were subjected to SDS-PAGE. The bands corresponding to MimG whose molecular mass was calculated to be $57915 \mathrm{kDa}$ based on the amino acid sequences were identified in the soluble fraction. Furthermore, we attempted to improve the expression of MimG protein by optimizing codon usage. However, E. coli cells containing the expression plasmid, namely, pCDFDmimGop, exhibiting the rare codon-modified $\operatorname{mim} G$, demonstrated the expression of MimG protein almost completely in the insoluble fraction (Fig. 3B). Hence, we employed the pCDFDmimG plasmid for subsequent experiments.

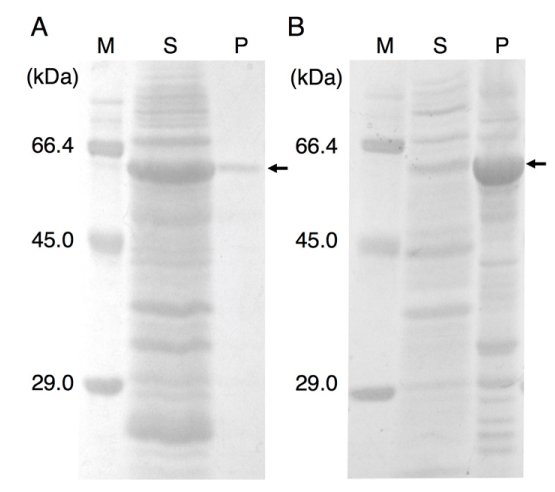

Figure 3. SDS-PAGE analysis of $E$. coli lysates expressing MimG with autoinduction medium (A) pCDFDmimG and (B) pCDDFmimG $\mathrm{p}_{\mathrm{op}}$. M, Marker; S, Soluble fraction; P, Precipitation fraction. The arrows indicate the expressed proteins.

\section{Characterization of $\mathrm{MimG}$}

The GroEL and MimG were purified by affinity chromatography. A single band corresponding to each, GroEL and MimG, was observed in SDS-PAGE results, suggesting that the proteins could be isolated in a homogenous state (Fig. 4A, B).

To confirm the subunit structure of the isolated GroEL-like protein, namely, MimG, the samples were subjected to blue native PAGE, which involves native PAGE analysis in the presence of the coomassie blue dye performed under nondenaturing conditions. A single band was observed corresponding to GroEL from $E$. coli in accordance with previous reports (Fig. 4C). ${ }^{35}$ This was consistent with the report stating that the crystal structure of GroEL shows a porous cylinder of 14 subunits in the dimer of heptamers. ${ }^{36}$ In contrast, two bands corresponding to MimG were observed, one of which demonstrated almost the same mobility as that by GroEL. The molecular mass of MimG was determined to be $8.5 \times 10^{5} \mathrm{Da}$ (Fig. 4D). The molecular mass of one of the bands was calculated to be $4.2 \times 10^{5} \mathrm{Da}$. Hence, the band denoted its heptamer region. Thus, the observation of the additional band of MimG suggests that the binding affinity between two MimG heptamers might be weaker than that of the GroEL. MimG is responsible for the 
functional expression of MimA and MimC hydroxylase components since the co-expression of MimG results in the solubility of MimA and MimC in E. coli cells. ${ }^{24}$ Additionally, we observed that the recombinant MimG protein could be assembled in a similar structure (the dimer of heptamers) to that of the GroEL from E. coli, indicating that MimG serves as a molecular chaperon similar to GroEL.

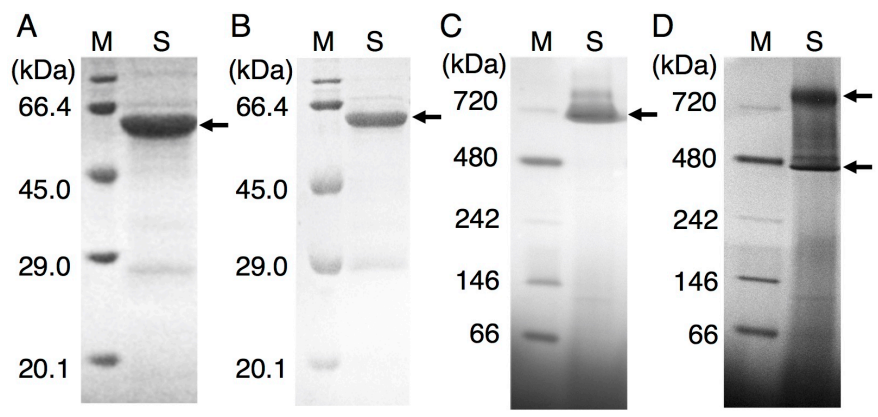

Figure 4. SDS-PAGE and blue native PAGE analysis of purified proteins. SDS-PAGE analysis of (A) GroEL and His-tag fused MimG (B); Blue native PAGE analysis of (C) GroEL and (D) His-tag fused MimG. M, Marker; S, Sample; The arrows indicate expressed proteins.

\section{Characterization of MimA and MimC}

As reported previously, E. coli cells expressing MimA, MimC, and MimG are capable of the oxidation of aromatic compounds. In support of this assertion, we were able to purify the His-tag fused recombinant hydroxylase component from $E$. coli cells upon simultaneous expression of MimA, MimC, and MimG. For affinity chromatography with $\mathrm{Ni}$-Sepharose resin, we introduced the His-tag sequence into the N-terminal site of the $\operatorname{mim} A$ gene in the pRSFDmimAC vector. The resulting sample of the affinity chromatography was subjected to anion-exchange chromatography for further purification. The purity was verified by SDS-PAGE, where two bands corresponding to the isolated MimA and Mim C were observed with molecular masses of 64 $\mathrm{kDa}$ and $41 \mathrm{kDa}$, respectively. These values are almost identical to the calculated values of $63293 \mathrm{kDa}$ for MimA and $41510 \mathrm{kDa}$ for Mim C, respectively. This indicated that MimA was successfully isolated, and the hydroxylase component consisted of another subunit, possibly MimC protein, resulting in the formation of MimAC complex (Fig. 5A). For further clarifications of this additional band, we conducted an LC/MS analysis of the hydroxylase component. The molecular masses corresponding to this band was determined to be $41542 \mathrm{kDa}$, which is almost identical to the calculated values of $41510 \mathrm{kDa}$. The densitometric analysis of two bands on SDS-PAGE gel showed a 1.0:1.2 ratio, demonstrating that the hydroxylase component is composed of Mim A and Mim C with an approximate ratio of $1: 1$.

To elucidate the subunit structure of the hydroxylase component, namely, the MimAC complex, we performed sizeexclusion chromatography. The MimAC complex protein showed a single peak in the chromatogram, suggesting that the MimAC complex was isolated as a single molecule in a homogenous state (Fig. 5B). The molecular mass was determined to be $1.9 \times 10^{5} \mathrm{Da}$ based on the elution volume. This suggested that the MimAC complex was a dimeric hydroxylase protein with two subunits in the $(\alpha \beta)_{2}$ stoichiometry, in accordance with previous predictions based on the arrangement of gene clusters. ${ }^{16}$ Based on the available structural information, the SDIMOs contain hydroxylase proteins composed of two or three subunits in a $(\alpha \beta \gamma)_{2}$ or $\alpha \beta$ quaternary structure.
Furthermore, no homologs to the $\gamma$ subunit in the gene cluster of group-5 SDIMOs, including the operons of $M$. smegmatis and $M$. godii, have been observed. ${ }^{27}$ Accordingly, it is likely that the hydroxylase component of group-5 SDIMOs differs in the quaternary structure from other SDIMOs reported to date.
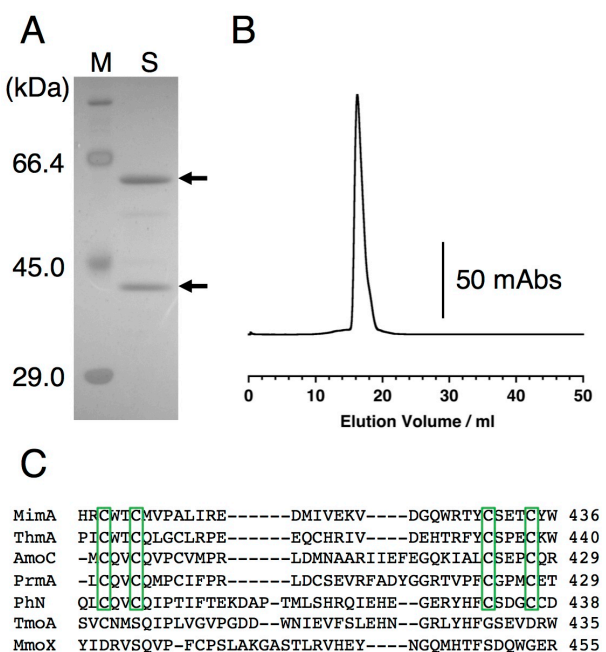

Figure 5. Characterization of purified MimAC complex. (A) Sizeexclusion chromatography, (B) Chromatogram of MimAC complex (C) Sequence alignment of the zinc-binding motif of SDIMO hydroxylase $\alpha$ subunits (The sequences of MimA from Mycolicibacterium goodii, ThmA from Pseudonocardia sp. K1, AmoC from Gordonia rubripertincta B-276, PrmA from Mycobacterium sp. TY-6, PhN from Pseudomonas stutzeri OX1, TmoA from Pseudomonas mendocina KR1, and MmoX from Methlococcus capsulatus Bath were aligned using ClustalW.)

To investigate whether the dinuclear metal center was formed, ICP-AES analysis was performed to quantify the amount of transition metals binding to the purified hydroxylase component. The iron content was determined to be 1.8 atoms per $\alpha \beta$ complex, suggesting that the dinuclear iron center was embedded in this enzyme. Other metals including $\mathrm{Co}, \mathrm{Ni}$, and $\mathrm{Cu}$ were not detected in the analysis. However, $1.4 \mathrm{Zn}$ atoms per $\alpha \beta$ complex was detected, suggesting that MimA contained at least one zinc-binding site. Among the SDIMOs, only group-1 SDIMO hydroxylase, for example, phenol hydroxylase from Pseudomonas stutzeri OX1, accommodates the zinc ion supported by four cysteine residues. ${ }^{20}$ These conserved cysteine residues, namely, Cys404, Cys407, Cys430, and Cys434 were observed in the MimA sequence, (Fig. 5C), demonstrating that they coordinate to the $\mathrm{Zn}$ ion in MimA protein similar to phenol hydroxylase of group-1 SDIMO, possibly stabilizing the scaffold.

\section{CONCLUSIONS}

We purified MimG, which is a group-5 SDIMO-associated GroEL-like protein via heterologous expression of group-5 SDIMOs and demonstrated its quaternary structure and assembly, which is almost identical to that of GroEL protein expressed in E. coli, which is one of the best characterized protein among the chaperonin protein family. This indicates that MimG plays a significant role in aiding the proper folding of the hydroxylase component. This study also demonstrated that the recombinant MimAC complex, namely the hydroxylase component that is co-expressed with MimG, exhibited a distinguished feature of $(\alpha \beta)_{2}$ quaternary structure and the zinc- 
binding site, indicating that the molecular properties of SDIMO are very diverse along with the variety of their sequences. These findings would extend our understanding of the biochemistry and enzymology of SDIMOs, which enhances the potential of the application to developing molecular tools for biocatalysis for the upgrading of light hydrocarbons as well as efficient bioremediation.

\section{ACKNOWLEDGEMENTS}

We appreciate the support from JST PRESTO (JPMJPR16S9). This work was funded by the Tonen General Sekiyu Research/Development Encouragement \& Scholarship Foundation.

\section{Author Contributions}

$\mathrm{NF}$ conceived and designed the experiments. CI YA performed the experiments. CI YA analyzed the data. NF wrote the paper.

\section{Competing interests}

The authors have declared that no competing interests exist.

\section{Corresponding Authors}

*fujieda@biochem.osakafu-u.ac.jp (NF)

\section{REFERENCES}

(1) Haynes, C. a; Gonzalez, R. Rethinking Biological Activation of Methane and Conversion to Liquid Fuels. Nat. Chem. Biol. 2014, 10 (5), 331-339. https://doi.org/10.1038/nchembio.1509.

(2) Fei, Q.; Guarnieri, M. T.; Tao, L.; Laurens, L. M. L. L.; Dowe, N.; Pienkos, P. T. Bioconversion of Natural Gas to Liquid Fuel: Opportunities and Challenges. Biotechnol. Adv. 2014, 32 (3), 596-614. https://doi.org/10.1016/j.biotechadv.2014.03.011.

(3) Lawton, T. J.; Rosenzweig, A. C. Methane-Oxidizing Enzymes: An Upstream Problem in Biological Gas-to-Liquids Conversion. J. Am. Chem. Soc. 2016, $138 \quad$ (30), 9327-9340. https://doi.org/10.1021/jacs.6b04568.

(4) Sun, M.; Zhang, J.; Putaj, P.; Caps, V.; Lefebvre, F.; Pelletier, J.; Basset, J. M. Catalytic Oxidation of Light Alkanes $\left(\mathrm{C}_{1}-\mathrm{C}_{4}\right)$ by Heteropoly Compounds. Chem. Rev. 2014, 114 (2), 981-1019. https://doi.org/10.1021/cr300302b.

(5) Lewis, J. C.; Coelho, P. S.; Arnold, F. H. Enzymatic Functionalization of Carbon-Hydrogen Bonds. Chem. Soc. Rev. 2011, 40 (4), 2003-2021. https://doi.org/10.1039/C0CS00067A.

(6) Torres Pazmiño, D. E.; Winkler, M.; Glieder, A.; Fraaije, M. W. Monooxygenases as Biocatalysts: Classification, Mechanistic Aspects and Biotechnological Applications. J. Biotechnol. 2010, 146 (1-2), 924. https://doi.org/10.1016/j.jbiotec.2010.01.021.

(7) Rojo, F. Degradation of Alkanes by Bacteria: Minireview. Environ. Microbiol. 2009, 11 (10), 2477-2490. https://doi.org/10.1111/j.14622920.2009.01948.x.

(8) Wang, V. C. C.; Maji, S.; Chen, P. P. Y.; Lee, H. K.; Yu, S. S. F.; Chan, S. I. Alkane Oxidation: Methane Monooxygenases, Related Enzymes, and Their Biomimetics. Chem. Rev. 2017, 117 (13), 8574-8621. https://doi.org/10.1021/acs.chemrev.6b00624.

(9) Sirajuddin, S.; Rosenzweig, A. C. Enzymatic Oxidation of Methane. Biochemistry 2015, $54 \quad$ (14), 2283-2294. https://doi.org/10.1021/acs.biochem.5b00198.
(10) Lipscomb, J. D. Biochemistry of the Soluble Methane Monooxygenase. Annual Review of Microbiology. 1994, pp 371-399. https://doi.org/10.1146/annurev.mi.48.100194.002103.

(11) Merkx, M.; Kopp, D. A.; Sazinsky, M. H.; Blazyk, J. L.; Muand̈ller, J.; Lippard, S. J. Dioxygen Activation and Methane Hydroxylation by Soluble Methane Monooxygenase: A Tale of Two Irons and Three Proteins. Angew. Chemie Int. Ed. 2001, 40 (15), 2782-2807. https://doi.org/10.1002/1521-3773(20010803)40:15<2782::AIDANIE2782>3.0.CO;2-P

(12) Hakemian, A. S.; Rosenzweig, A. C. The Biochemistry of Methane Oxidation. Annu. Rev. Biochem. 2007, 76, 223-241. https://doi.org/10.1146/annurev.biochem.76.061505.175355.

(13) Kotani, T.; Yamamoto, T.; Yurimoto, H.; Sakai, Y.; Kato, N. Propane Monooxygenase and $\mathrm{NAD}^{+}$-Dependent Secondary Alcohol Dehydrogenase in Propane Metabolism by Gordonia Sp. Strain TY-5.

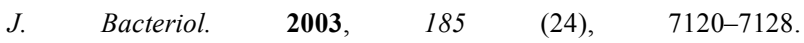
https://doi.org/10.1128/JB.185.24.7120-7128.2003.

(14) Kotani, T.; Kawashima, Y.; Yurimoto, H.; Kato, N.; Sakai, Y. Gene Structure and Regulation of Alkane Monooxygenases in PropaneUtilizing Mycobacterium Sp. TY-6 and Pseudonocardia Sp. TY-7. J. Biosci. Bioeng. 2006, $102 \quad$ (3), 184-192. https://doi.org/10.1263/jbb.102.184

(15) Leahy, J. G.; Batchelor, P. J.; Morcomb, S. M. Evolution of the Soluble Diiron Monooxygenases. FEMS Microbiol. Rev. 2003, 27 (4), 449-479. https://doi.org/10.1016/S0168-6445(03)00023-8.

(16) Notomista, E.; Lahm, A.; Di Donato, A.; Tramontano, A. Evolution of Bacterial and Archaeal Multicomponent Monooxygenases. J. Mol. Evol. 2003, 56 (4), 435-445. https://doi.org/10.1007/s00239-002-24141.

(17) Coleman, N. V.; Bui, N. B.; Holmes, A. J. Soluble Di-iron Monooxygenase Gene Diversity in Soils, Sediments and Ethene Enrichments. Environ. Microbiol. 2006, 8 (7), 1228-1239. https://doi.org/10.1111/j.1462-2920.2006.01015.x.

(18) Osborne, C. D.; Haritos, V. S. Beneath the Surface: Evolution of Methane Activity in the Bacterial Multicomponent Monooxygenases. Mol. Phylogenet. Evol. 2019, 139 (June), 106527. https://doi.org/10.1016/j.ympev.2019.106527.

(19) Rosenzweig, A. C.; Frederick, C. A.; Lippard, S. J.; Nordlund, Pär. Crystal Structure of a Bacterial Non-Haem Iron Hydroxylase That Catalyses the Biological Oxidation of Methane. Nature 1993, 366 (6455), 537-543. https://doi.org/10.1038/366537a0.

(20) Sazinsky, M. H.; Dunten, P. W.; McCormick, M. S.; Di Donato, A.; Lippard, S. J. X-Ray Structure of a Hydroxylase-Regulatory Protein Complex from a Hydrocarbon-Oxidizing Multicomponent Monooxygenase, Pseudomonas Sp. OX1 Phenol Hydroxylase. Biochemistry 2006, $45 \quad$ (51), $15392-15404$. https://doi.org/10.1021/bi0618969.

(21) Sazinsky, M. H.; Bard, J.; Di Donato, A.; Lippard, S. J. Crystal Structure of the Toluene/o-Xylene Monooxygenase Hydroxylase from Pseudomonas Stutzeri OX1: Insight into the Substrate Specificity, Substrate Channeling, and Active Site Tuning of Multicomponent Monooxygenases. J. Biol. Chem. 2004, 279 (29), 30600-30610. https://doi.org/10.1074/jbc.M400710200.

(22) Miura, A.; Dalton, H. Purification and Characterization of the Alkene Monooxygenase from Nocardia Corallina B-276. Biosci. Biotechnol. Biochem. 1995, 59 (5), 853-859. https://doi.org/10.1271/bbb.59.853. 
(23) Carlin, D. a.; Bertolani, S. J.; Siegel, J. B. Biocatalytic Conversion of Ethylene to Ethylene Oxide Using an Engineered Toluene Monooxygenase. Chem. Commun. 2015, 51 (12), 2283-2285. https://doi.org/10.1039/C4CC08802F.

(24) Furuya, T.; Hayashi, M.; Kino, K. Reconstitution of Active Mycobacterial Binuclear Iron Monooxygenase Complex in Escherichia Coli. Appl. Environ. Microbiol. 2013, 79 (19), 6033-6039. https://doi.org/10.1128/AEM.01856-13.

(25) Lloyd, J. S.; Finch, R.; Dalton, H.; Murrell, J. C. Homologous Expression of Soluble Methane Monooxygenase Genes in Methylosinus Trichosporium OB3b. Microbiology 1999, 145 (2), 461-470. https://doi.org/10.1099/13500872-145-2-461.

(26) McCarl, V.; Somerville, M. V; Ly, M.; Henry, R.; Liew, E. F.; Wilson, N. L.; Holmes, A. J.; Coleman, N. V. Heterologous Expression of Mycobacterium Alkene Monooxygenases in Gram-Positive and GramNegative Bacterial Hosts. Appl. Environ. Microbiol. 2018, 84 (15), 116. https://doi.org/10.1128/AEM.00397-18.

(27) Furuya, T.; Hirose, S.; Osanai, H.; Semba, H.; Kino, K. Identification of the Monooxygenase Gene Clusters Responsible for the Regioselective Oxidation of Phenol to Hydroquinone in Mycobacteria. Appl. Environ. Microbiol. 2011, 77 (4), 1214-1220. https://doi.org/10.1128/AEM.02316-10.

(28) Furuya, T.; Hayashi, M.; Semba, H.; Kino, K. The Mycobacterial Binuclear Iron Monooxygenases Require a Specific Chaperonin-like Protein for Functional Expression in a Heterologous Host. FEBS J. 2013, 280 (3), 817-826. https://doi.org/10.1111/febs.12070.

(29) Stafford, G. P.; Scanlan, J.; McDonald, I. R.; Murell, J. C. RpoN, MmoR and MmoG, Genes Involved in Regulating the Expression of Soluble Methane Monooxygenase in Methylosinus Trichosporium OB3b. Microbiology 2003, $149 \quad$ (7), $1771-1784$. https://doi.org/10.1099/mic.0.26060-0.

(30) Scanlan, J.; Dumont, M. G.; Murrell, J. C. Involvement of MmoR and MmoG in the Transcriptional Activation of Soluble Methane Monooxygenase Genes in Methylosinus Trichosporium OB3b. FEMS Microbiol. Lett. 2009, 301 (2), 181-187. https://doi.org/10.1111/j.15746968.2009.01816.x.

(31) Kurth, E. G.; Doughty, D. M.; Bottomley, P. J.; Arp, D. J.; SayavedraSoto, L. A. Involvement of BmoR and BmoG in N-Alkane Metabolism in "Pseudomonas Butanovora." Microbiology 2008, 154 (1), 139-147. https://doi.org/10.1099/mic.0.2007/012724-0.

(32) Teshima, T.; Mashimo, S.; Kondo, A.; Fukuda, H. Affinity Purification and Immobilization of Fusion Chaperonin GroEL-(His)6 and Its Utilization to Mediate Protein Refolding. J. Ferment. Bioeng. 1998, 86 (4), 357-362. https://doi.org/10.1016/S0922-338X(99)89004-7.

(33) Studier, F. W. Protein Production by Auto-Induction in High Density Shaking Cultures. Protein Expr. Purif. 2005, 41 (1), 207-234. https://doi.org/10.1016/j.pep.2005.01.016.

(34) Gill, S. C.; von Hippel, P. H. Calculation of Protein Extinction Coefficients from Amino Acid Sequence Data. Anal. Biochem. 1989, 182 (2), 319-326. https://doi.org/10.1016/0003-2697(89)90602-7.

(35) Vilasi, S.; Carrotta, R.; Mangione, M. R.; Campanella, C.; Librizzi, F.; Randazzo, L.; Martorana, V.; Gammazza, A. M.; Ortore, M. G.; Vilasi, A.; et al. Human Hsp60 with Its Mitochondrial Import Signal Occurs in Solution as Heptamers and Tetradecamers Remarkably Stable over a Wide Range of Concentrations. PLoS One 2014, 9 (5). https://doi.org/10.1371/journal.pone.0097657.
(36) Braig, K.; Otwinowskitt, Z.; Hegdett, H.; Boisvert, D. C.; Joachimiakt, A.; Horwich, A. L.; Sigler Tt, P. B. The Crystal Structure of the Bacterial Chaperonin GroEL at 2.8 A Crystallization and Structure Determination. Nature 1994, 371 (October), 578-586. 